\title{
Are women adequately informed before gynaecological surgery?
}

\author{
Mojgan Pakbaz ${ }^{1 *} \mathbb{D}$, Ewa Rolfsman ${ }^{2}$ and Mats Löfgren ${ }^{1}$
}

\begin{abstract}
Background: Surgery for pelvic organ prolapse, urinary incontinence, and hysterectomy are the most common gynaecological surgeries that can affect the function of the bladder and bowel as well as one's sexual life. There is evidence that adequate patient information given preoperatively regarding expected outcomes of surgery is important because well-informed patients are more satisfied with the results of surgery and recover faster. However, there is little known about the amount and quality of information given to women before surgery. This study investigates whether women received information before gynaecological surgery on the effect of surgery with respect to the functioning of the bladder (micturition, ability to stay continent) and the bowel (empty bowel) as well as the surgery's effect on sexual functioning.

Methods: A prospective, cross-sectional study was conducted. Women undergoing hysterectomy, surgery for vaginal prolapse, or surgery for urinary incontinence $(n=972)$ and included in the Swedish National Register for Gynaecological Surgery participated in the study. A questionnaire was developed and distributed to the women along with the preoperative questionnaire from the register.

Results: About 50\% of the women undergoing prolapse surgery were supplied with information regarding the effect of the surgery with respect to remaining continent, to emptying bowels, micturitaion, and sexual life. One out of four women undergoing hysterectomy received information about the effect of the surgery on the sexual life and bladder function. In the incontinence group, the given information about the surgery's effect on bladder function and sexual function was 80 and 30\%, respectively.
\end{abstract}

Conclusion: Surgery in the vagina and the genital organs may affect function of the organs close to the surgical area (i.e., bladder and bowel) and may affect sexual function. According to this study, women are inadequately informed before surgery. Access to information via oral and written counselling needs to be improved.

Keywords: Preoperative information, Benign gynaecological surgery

\section{Background}

Each year, approximately 17,000 women in Sweden undergo surgery for pelvic organ prolapse (POP), urinary incontinence (UI), or hysterectomy on benign indication [1].

Symptoms associated with POP are complex. Women with prolapse may present with a variety of symptoms from the bladder (frequency, urgency, and urinary incontinence) and/or the bowel (problems emptying and faecal incontinence) [2]. Prolapse may have a negative effect on a woman's sexual life [2-5]. It is also known that after surgery while some symptoms improve, others may remain unchanged.

\footnotetext{
*Correspondence: Mojgan.Pakbaz@umu.se

'Department of Clinical Sciences, Obstetrics and Gynaecology, Umeå

University, SE-901 87 Umeå, Sweden

Full list of author information is available at the end of the article
}

Furthermore, there is also a risk that new undesirable symptoms may arise [2]. Concerning hysterectomy, its effect on sexual activity and occurrence of urinary incontinence has been debated. Some studies have found that hysterectomy has no effect on sexual activity and symptoms of UI, whereas a negative effect on sexuality and appearance of UI has been reported in other studies [6-8]. Surgery for UI has been shown to have a positive effect on sexual function [9-11], but its effect on bowel function is unknown.

Previous studies have suggested that women, particularly those with vaginal prolapse, have little access to publicly available information on prolapse [3, 12]. Informing women not only about the expected positive effects but also about conceivable side effects of an 
operation is an essential part of the decision-making that may lead to surgery $[13,14]$, since there is evidence that well-informed patients are more satisfied with the results of surgery and recover faster [13]. This study investigates the quality and amount of information that women receive from the surgeon before a gynaecological surgery on benign indication regarding the effect of the operation on urinary function, bowel function, and sexual function.

\section{Methods}

This was a prospective, cross-sectional study based on a combination of medical data included in the Swedish National Register for Gynaecological Surgery (the Gynop-register) and data from a complementary questionnaire distributed to women undergoing benign surgery [15]. The study included women with planned hysterectomy $(n=385)$, surgery for POP $(n=307)$, or surgery for UI $(n=280)$. The complementary questionnaire was validated and distributed to the women along with the preoperative questionnaire. The complementary questionnaire consisted of open-ended and multiplechoice questions (Additional files 1 and 2). The questionnaire included items requesting the women's own description of POP and its causes, and the source of information on their own condition for which they contacted the gynaecology department [12]. In addition, the questionnaire included questions about whether they have been informed by the physician about the surgery and its effect on sexuality, urinary function (ability of being/staying continent and micturition), and bowel function (emptying bowel) with a "yes" or "no" answer. The study period was March 1 through November 31, 2010 and the response rate was $95 \%$. The data set included medical data reported by patients and surgeons, patientreported symptoms, and questions regarding whether women had an active role in the decision-making process before surgery.

Women in the prolapse group underwent surgery in one or several compartments and of these 14\% underwent vaginal hysterectomy. All women in the incontinence group had surgery with synthetic sling (retropubic or transobturator) without concomitant prolapse surgery. Of the women in the hysterectomy group, $71 \%$ underwent abdominal surgery, $2 \%$ underwent laparoscopic hysterectomy, and $27 \%$ underwent vaginal hysterectomy. Data were analysed using SPSS v. 19.0 and are presented as mean \pm standard deviation or number and percentage.

\section{Results}

Characteristics of the participants are given in Table 1. In the prolapse group, the proportion of women who received information regarding the effect of surgery on bladder, bowel, and sexual function ranged from 38 to $53 \%$ (Table 2). Almost 50\% of the women in the prolapse
Table 1 Characteristics of the participants

\begin{tabular}{llll}
\hline Characteristic & $\begin{array}{l}\text { Prolapse } \\
(n=307)\end{array}$ & $\begin{array}{l}\text { Incontinence } \\
(n=280)\end{array}$ & $\begin{array}{l}\text { Hysterectomy } \\
(n=385)\end{array}$ \\
\hline Age & $59 \pm 10.2$ & $50 \pm 10.3$ & $46 \pm 7.2$ \\
BMI & $26 \pm 3.8$ & $27.4 \pm 10.2$ & $27 \pm 4.9$ \\
$\begin{array}{l}\text { Education } \\
\quad 9 \text { years or less }\end{array}$ & $88(29)$ & $46(16)$ & $52(14)$ \\
$\begin{array}{l}\text { High school } \\
\text { degree }\end{array}$ & $81(26)$ & $106(38)$ & $169(44)$ \\
$\begin{array}{l}\text { University } \\
\text { degree }\end{array}$ & $124(40)$ & $126(45)$ & $156(41)$ \\
$\begin{array}{l}\text { Menopause } \\
\text { Current smoker }\end{array}$ & $21(6)$ & $14(5)$ & $11(3)$ \\
$\begin{array}{l}\text { Co-morbidity } \\
\text { Diabetes mellitus }\end{array}$ & $10(3)$ & $10(4)$ & $70(18)$ \\
$\quad$ Hypertension & $85(28)$ & $65(23)$ & $66(17)$ \\
$\begin{array}{l}\text { Previous caesarean } \\
\text { section }\end{array}$ & $19(6)$ & $27(10)$ & $44(11)$ \\
\hline
\end{tabular}

All values are expressed as mean \pm standard deviation or as number (\%)

group reported symptoms of UI, difficulty emptying bowel, and/or micturition problems, but only half of them had received information about the effect of surgery on these symptoms (Table 3). One out of six women in the prolapse group reported that prolapse had negatively affected their sexual life, but almost $40 \%$ of them had been informed about whether surgery may affect their sexual life (Table 3).

The majority of women in the incontinence group reported that they had received information concerning the effect of incontinence surgery on their ability to stay continent $(82 \%)$ and micturition problems $(63 \%)$ (Table 2 ). However, the information given about the effect of surgery on bowel function or sexuality in this group was only in 20 and $30 \%$ of cases. UI negatively affected sexual life in $7 \%$ of women in the incontinence group; however, only $30 \%$ of these women had received information about the possible effects of surgery on their problem (Table 3).

A relatively small proportion of the women in the hysterectomy group reported that they had been informed

Table 2 Information given regarding the effects of surgery on micturition, sexuality, ability to stay continent, and emptying bowel

\begin{tabular}{llll}
\hline & $\begin{array}{l}\text { Prolapse } \\
(n=307)\end{array}$ & $\begin{array}{l}\mathrm{UI}^{\mathrm{a}} \\
(n=280)\end{array}$ & $\begin{array}{l}\text { Hysterectomy } \\
(n=385)\end{array}$ \\
\hline Micturition & $152(50)$ & $176(63)$ & $89(23)$ \\
Sexuality & $123(40)$ & $83(30)$ & $98(25)$ \\
$\begin{array}{l}\text { Ability to stay } \\
\text { continent }\end{array}$ & $163(53)$ & $230(82)$ & $88(23)$ \\
Emptying bowel & $118(38)$ & $56(20)$ & $65(17)$ \\
\hline
\end{tabular}

All values are expressed as number (\%)

${ }^{a} U /$ urinary incontinence 
Table 3 Information given in relation to the symptoms reported by the study population

\begin{tabular}{|c|c|c|c|}
\hline & $\begin{array}{l}\text { Prolapse } \\
(n=307)\end{array}$ & $\begin{array}{l}\text { UI } \\
(n=280)\end{array}$ & $\begin{array}{l}\text { Hysterectomy } \\
(n=385)\end{array}$ \\
\hline Reported UI & $134(44)$ & $268(96)$ & $104(27)$ \\
\hline Received information & $77(57)$ & $222(83)$ & $20(19)$ \\
\hline $\begin{array}{l}\text { Reported micturation } \\
\text { problem }\end{array}$ & $128(42)$ & $41(15)$ & $73(19)$ \\
\hline Received information & $70(55)$ & $25(61)$ & $21(29)$ \\
\hline $\begin{array}{l}\text { Reported difficulty } \\
\text { emptying bowel }\end{array}$ & $139(45)$ & $75(27)$ & $113(29)$ \\
\hline Received information & $60(43)$ & $13(17)$ & $16(14)$ \\
\hline $\begin{array}{l}\text { Reported negative impact } \\
\text { on sexuality }\end{array}$ & $50(16)$ & $20(7)$ & - - - ${ }^{a}$ \\
\hline Received information & $19(38)$ & $6(30)$ & - - \\
\hline
\end{tabular}

All values are expressed as number (\%)

aThe Ethical Board did not approve this question for inclusion in the register for women undergoing hysterectomy for benign indication (fibromas and dysfunctional bleeding)

by the surgeon about the effects of the operation on urinary, bowel, and sexual function (17-25\%) (Table 2). In this group, 29\% reported bowel symptoms (feeling of incomplete emptying), $27 \%$ reported UI, and $19 \%$ reported micturation difficulties (Table 3). However, the information given by the surgeons about the effect of surgery for each of these problems had reached only 14, 19 , and $29 \%$ of the patients, respectively. The majority of women (95\%) in each group reported that they had been involved in the decision to have surgery.

\section{Discussion}

In this study, we investigated whether women received information from the surgeon before surgery for prolapse, urinary incontinence, or hysterectomy concerning the possible effects of surgery on bladder function, bowel function, and sexual function. We chose these three groups of women because these surgeries are common and they may also influence urinary tract function, bowel function, and sexual function either in a positive or a negative way. The only symptom related to vaginal prolapse that one can be sure of being relieved of after surgery is the sensation of bulging. Other symptoms related to bowel, bladder, or sexual function among women with prolapse can either be improved [11, 16-18], remain unaltered, or even become worse after surgery [19, 20]. Against this background, every woman who undergoes surgery for prolapse should be adequately informed about the effects and side effects of the surgery regarding sexual function and functioning of the bladder and the bowel. In this study, the proportion of women who did receive information from the surgeon regarding the probable effect of the surgery on the functioning of the bowel, the bladder, and sexual life is low. This proportion ranged in the interval of one out of three to every other woman.

It has been debated whether hysterectomy and vaginal hysterectomy in particular (due to prolapse or for any other reason) contributes to the development of urinary incontinence [21]. The effect of hysterectomy on sexual function has also been discussed. According to some studies, hysterectomy may influence sexuality in a negative way [6]. However, other studies have indicated that sexual function remains unaltered after hysterectomy [16]. It is also known that bowel function may be disturbed for a short while after abdominal hysterectomy, but preexisting bowel dysfunction is often related to other causes and a hysterectomy does not alter this dysfunction [22, 23]. Nevertheless, few women undergoing hysterectomy in this study received preoperative information on surgery's influence on bladder, bowel, and sexual function.

Furthermore, there is a major difference between hysterectomy group and POP group regarding the amount of information they are given preoperatively and this may be explained by different symptoms in each group leading to the decision for surgery. Fibroma and bleeding disorders were the main reasons for surgery in the hysterectomy group, whereas in the prolapse group in addition to the bulging symptom other symptoms from bladder and bowel can interfere with the decision for surgery. Therefore, the prolapse group received information in a higher degree regarding effect of surgery on the function of the bowel, bladder, and sexual life than women undergoing hysterectomy.

Midurethral sling is a surgical method for treatment of stress-related urinary incontinence. Women with coexisting urge incontinence have a reduced success rate after surgery [24]. In our study, women in the incontinence group were provided with information regarding the effects of surgery on their UI to a high degree. The effect of midurethral sling surgery on sexuality is debated $[25,26]$. Improvement of sexual life due to cure of coital incontinence after surgery has been reported [25]. One of the rare but known complications after sling plastic, in particular the transobturator sling, is dyspareunia [26]. In this study, women were seldom provided with information regarding influence of surgery on sexual function.

\section{Strengths and limitations}

Data used in this study are from the Gynop-register, which is a national register and includes all women undergoing gynaecological surgery in Sweden at both university hospitals as well as county hospitals. Therefore, there is no selection bias for patients included in this study. A limitation of this study is the recall bias. It could be that the surgeon does mention some information on the effect of surgery on bladder, bowel, and sexual function, but the 
patients do not remember because the amount of information can be overwhelming.

\section{Conclusion}

The present study shows that women are not adequately informed before gynaecological surgery. Given the conflicting evidence on the effect of the surgeries, it is important to convey these uncertainties to the patient. There is need to improve the access of information to women through oral counselling and/or written information before surgery. Therefore, national patient information on postoperative course and effect of prolapse surgery on nearby organs has been conducted and is now more accessible for patients undergoing POP surgery in Sweden. National patient information for other gynaecological surgery is now being developed. Further prospective studies are needed that investigate whether this effort may lead to satisfaction in outcome of surgery.

\section{Additional files}

Additional file 1: The study questionnaire translated in English. It consists of open-ended and multiple-choice questions responded by three groups of patients with a scheduled surgery for vaginal prolapse, urinary incontinence or bleeding disorder with a hysterectomy. (DOC 47 kb)

Additional file 2: The study questionnaire in Swedish language. (DOC 54 kb)

\section{Abbreviations}

POP: Pelvic organ prolapse; The Gynop-register: The Swedish National Register for Gynaecological Surgery; UI: Urinary incontinence

\section{Acknowledgements}

The authors would like to thank the study participants.

\section{Funding}

This study was supported by grants from The Swedish Association of Local Authorities and Regions.

\section{Availability of data and materials}

The data are not openly shared due to data protection regulations. All patient data are included in the Swedish National Register for Gynaecological Surgery and are available upon request from the corresponding author.

\section{Authors' contributions}

MP was involved in data collection, data analysis, and manuscript writing. ML was involved in study design and data analysis. ER participated in the design of the study. All authors read and approved the final manuscript.

\section{Ethics approval and consent to participate}

The study was approved by the Regional Ethics Review Board in Umeå, Sweden (D. no. 2010-31-32). In accordance with the regulations of the management of the National Health Quality Registers in Sweden, patients had received written information on the register and they had an opportunity to decline participation in the register. Eligible participants received written information on the aims of the study, including assurances that the questionnaire was for research purposes and participation was voluntarily. They were also assured that their individual integrity would be protected.

\section{Consent for publication}

The written information provided to the participants stated that if the study questionnaire is answered and returned to the researcher, the data will be included in the study for publication.

\section{Competing interests}

Mats Löfgren is chairman of the Gynop-register. No conflicts of interest are reported for Mojgan Pakbaz and Ewa Rolfsman. The authors alone are responsible for the content of the paper.

\section{Publisher's Note}

Springer Nature remains neutral with regard to jurisdictional claims in published maps and institutional affiliations.

\section{Author details}

${ }^{1}$ Department of Clinical Sciences, Obstetrics and Gynaecology, Umeå University, SE-901 87 Umeå, Sweden. ${ }^{2}$ Department of Applied Educational Science, Umeå University, Umeå, Sweden.

Received: 3 December 2015 Accepted: 18 August 2017

Published online: 25 August 2017

\section{References}

1. Socialstyrelsen. Statistikdatabas. [cited 201117 January]; Available from: http://www.socialstyrelsen.se/statistik/statistikdatabas.

2. Jelovsek JE, Maher C, Barber MD. Pelvic organ prolapse. Lancet. 2007; 369(9566):1027-38.

3. Pakbaz M, Persson M, Lofgren M, Mogren I. 'A hidden disorder until the pieces fall into place'-a qualitative study of vaginal prolapse. BMC Womens Health. 2010;10:18

4. Maher C, Feiner B, Baessler K, Adams EJ, Hagen S, Glazener CM. Surgical management of pelvic organ prolapse in women. Cochrane Database Syst Rev. 2010:4:CD004014.

5. Jelovsek JE, Barber MD. Women seeking treatment for advanced pelvic organ prolapse have decreased body image and quality of life. Am J Obstet Gynecol. 2006;194(5):1455-61.

6. Forsgren C, Lundholm C, Johansson AL, Cnattingius S, Zetterstrom J, Altman D. Vaginal hysterectomy and risk of pelvic organ prolapse and stress urinary incontinence surgery. Int Urogynecol J. 2012;23(1):43-8.

7. Engh MA, Otterlind L, Stjerndahl JH, Lofgren M. Hysterectomy and incontinence: a study from the Swedish national register for gynecological surgery. Acta Obstet Gynecol Scand. 2006:85(5):614-8.

8. de Tayrac R, Chevalier N, Chauveaud-Lambling A, Gervaise A, Fernandez H. Risk of urge and stress urinary incontinence at long-term follow-up after vaginal hysterectomy. Am J Obstet Gynecol. 2004;191(1):90-4.

9. Rogers GR, Villarreal A, Kammerer-Doak D, Qualls C. Sexual function in women with and without urinary incontinence and/or pelvic organ prolapse. Int Urogynecol J Pelvic Floor Dysfunct. 2001;12(6):361-5.

10. Handa VL, Cundiff $\mathrm{G}$, Chang HH, Helzlsouer KJ. Female sexual function and pelvic floor disorders. Obstet Gynecol. 2008;111(5):1045-52.

11. Weber AM, Walters MD, Piedmonte MR. Sexual function and vagina anatomy in women before and after surgery for pelvic organ prolapse and urinary incontinence. Am J Obstet Gynecol. 2000;182(6):1610-5.

12. Pakbaz M, Rolfsman E, Mogren I, Lofgren M. Vaginal prolapse-perceptions and healthcare-seeking behavior among women prior to gynecological surgery. Acta Obstet Gynecol Scand. 2011;90(10):1115-20.

13. Bovbjerg VE, Trowbridge ER, Barber MD, Martirosian TE, Steers WD, Hullfish KL. Patient-centered treatment goals for pelvic floor disorders: association with quality-of-life and patient satisfaction. Am J Obstet Gynecol. 2009; 200(5):568 e1-6.

14. Hullfish KL. Pelvic floor dysfunction-what do women really want? J Urol. 2008;179(6):2092-3.

15. Gynop.org. [internet] Umeå: Gynop-registret; [cited 2010 oktober 28]; Available from: www.gynop.org/english/about/quests.htm.

16. Thakar R, Chawla S, Scheer I, Barrett G, Sultan AH. Sexual function following pelvic floor surgery. Int J Gynaecol Obstet. 2008;102(2):110-4.

17. Nguyen JK, Bhatia NN. Resolution of motor urge incontinence after surgical repair of pelvic organ prolapse. J Urol. 2001;166(6):2263-6.

18. Digesu GA, Salvatore S, Chaliha C, Athanasiou S, Milani R, Khullar V. Do overactive bladder symptoms improve after repair of anterior vaginal wall prolapse? Int Urogynecol J Pelvic Floor Dysfunct. 2007;18(12):1439-43.

19. Tunuguntla HS, Gousse AE. Female sexual dysfunction following vaginal surgery: a review. J Urol. 2006;175(2):439-46.

20. Helstrom L, Nilsson B. Impact of vaginal surgery on sexuality and quality of life in women with urinary incontinence or genital descensus. Acta Obstet Gynecol Scand. 2005;84(1):79-84. 
21. Forsgren. Hysterectomy on benign indications and pelvic floor dysfunction clinical and epidemiological aspects. Stockholm: Karolinska Institutet; 2009.

22. Goffeng AR, Andersch B, Antov S, Berndtsson I, Oresland T, Hulten L. Does simple hysterectomy alter bowel function? Ann Chir Gynaecol. 1997;86(4):298-303.

23. Lashen H, Jones GL, Duru C, Pitsillides C, Radley S, Jacques RM, et al. Bowel dysfunction after total abdominal hysterectomy for benign conditions: a prospective longitudinal study. Eur J Gastroenterol Hepatol. 2013;25(10):1217-22.

24. Nilsson M, Lalos $\mathrm{O}$, Lindkvist $\mathrm{H}$, Lofgren $\mathrm{M}$, Lalos A. Female urinary incontinence: patient-reported outcomes 1 year after midurethral sling operations. Int Urogynecol J. 2012;23(10):1353-9.

25. Nilsson $\mathrm{M}$, Lalos $\mathrm{A}$, Lalos $\mathrm{O}$. The impact of female urinary incontinence and urgency on quality of life and partner relationship. Neurourol Urodyn. 2009; 28(8):976-81.

26. Cholhan HJ, Hutchings TB, Rooney KE. Dyspareunia associated with paraurethral banding in the transobturator sling. Am J Obstet Gynecol. 2010:202(5):481 e1-5.

Submit your next manuscript to BioMed Central and we will help you at every step:

- We accept pre-submission inquiries

- Our selector tool helps you to find the most relevant journal

- We provide round the clock customer support

- Convenient online submission

- Thorough peer review

- Inclusion in PubMed and all major indexing services

- Maximum visibility for your research

Submit your manuscript at www.biomedcentral.com/submit 